\title{
The exploration on work method which about Youth ideological guidance
}

\author{
Ren Xue yan ${ }^{1, \text { a }}$, \\ ${ }^{1}$ Unitied Front Work Department, Jilin Animation Institute Changchun,china \\ alvzhixue_2007@sina.com
}

\begin{abstract}
Put the basic moral education in a prominent position. We must fully understand the importance of moral education in youth education, and the youth should follow the law of growth. Based on actual experience and level of knowledge of young people of different ages, we had better to design to educate and guide the scientific content, vigorously carry forward the socialist concept of honor. Deepen the ideological and moral construction of youth and guide youth to develop good habits from the start, from the trivial, to distinguish between right and wrong, good and evil, discernment, and love. Extensive moral education, establish a respectable, amiable, learnable moral example and guide young people to promote social morality, professional ethics and family virtues, conscientiously fulfill their legal obligations. To become a courtesy, honesty and responsible man.
\end{abstract}

Keywords-The Communist Youth League Young minds Guidelines Method

\section{INTRODUCTION}

\section{I.LEAGUE ORGANIZATION'S PROBLEM IN THE WORK OF DEVELOPING YOUTH THOUGHT LEADING}

\section{A.Less attention paid to Youth Thought Leading Work.}

Someone thought that Youth Thought Leading Work is macroscopically, the speaking is more important than doing. Someone thought that Youth Thought Leading Work is a slow work, lots of work are being done, but the achievements are limited. Many elements affect the outcomes, sometime more attention is put on the work that is assigned by the superior, less on the Youth Thought Leading Work, the affected Youth Initiative is weaken.

\section{B.Serving Leading Ability Lack.}

If the Youth Thought Leading Work can be accepted by the Youth and if the Youth can be affected, heavily depending on the ability and level of the Communist Youth League Serving Leading Youth. Group and League Organization urgently need the scientific marketing theory to improve the work, according to the youth requirement and realistic situation to decide their work direction and work plan. Strengthen the Serving Leading, stick the aim of educating people, according to Youth's requirement and difficulties to solve the hot and difficult problems the Youth concern to lead the Youth.

\section{C.The Youth's requirements are not held.}

With the developing of the society, the Youth's requirements are more and more diverse, the possibilities of choosing are diversifying. Under this circumstance, it needs us to talk to people closely to understand and hold the
Youth's requirements. On the contrary, lack of effective info path and work method, no initiative to understand, depending on the subjective judgment to make decisions, will break away from the Youth's requirement and go to the opposite way against the Youth's requirement. According to the research, currently the common problem in the Thought Leading Work in the Communist Youth League is the method adapt the Youth Changing and Youth Feature

\section{D.The ability of applying New Media to develop Leading Work needs to improve.}

In recent year, the Communist Youth League who applies New Media to develop Leading Youth Work gains some effect, though gaining some achievement in Mobile News Paper, WeiBo etc. but still there are some flaws and gap. For instance, there are some gap in how to use "Web Language" and the New Media Transform Regulation' form to connect, communicate, serve with the Youth, and how to lead and win the speech right in Weibo, Forum, Social Web to improve the Public Opinion Leading Ability, the Communist Youth League still can not develop the essential function in New Media area.

\section{E.Be weak in applying art, fashion to develop work.}

With the improving of our economy and people's living level, the cultural industry develops well, the cultural consumption is going up. Accompanying with this course, the Youth's study, living, work, entertainment, reading form are affected by cultural products gradually such as film, TV, animation, music, fashion etc. and one step closer to affect their Sense of Worth. In our Leading Work, we are weak in asking for major power, market power, putting right thoughts into the cultural product, and limited in traditional form. Cultural art fashion element can not be applied, it's hard to attract the Youth.

\section{II.COUNTERMEASURES TO GUIDE THE WORK OF YOUTH THOUGHT.}

A. on leading content, it should pinpoint the fundamental goal of the campaign.

Seeming the rational belief education as the key point. Arming and educating the young with the system of theories of socialism and Chinese characteristics persistently, continue to intensify the ideal faith education in youth, on the national conditions, modern history and the history of the Party knowledge education. Around the study of the spirit of the 18th CPC National Congress and implement the Party, the spirit of the 17th CPC National Congress and a series of major events such as "my Chinese dream", we launched the "dialogue with faith", "studying the history of the Party, 
understanding the information of the Party, going with the Party" thematic education activities, such as guiding teenagers consciously to put their personal ideals into the common ideal of socialism with Chinese characteristics, going with Party firmly walk the road of socialism with Chinese characteristics.

Put the basic moral education in a prominent position. We must fully understand the importance of moral education in youth education, and the youth should follow the law of growth. Based on actual experience and level of knowledge of young people of different ages, we had better to design to educate and guide the scientific content, vigorously carry forward the socialist concept of honor. Deepen the ideological and moral construction of youth and guide youth to develop good habits from the start, from the trivial, to distinguish between right and wrong, good and evil, discernment, and love. Extensive moral education, establish a respectable, amiable, learnable moral example and guide young people to promote social morality, professional ethics and family virtues, conscientiously fulfill their legal obligations. To become a courtesy,honesty and responsible man.

Regard the training of qualified socialist builders and successors China characteristics as the fundamental task of the mission. Center on persisting and developing socialism with China characteristics, put the rational belief education as the core, carry out the "my China dream" theme educational activities, use the China dream tamp the majority of young people's common ideological base, arm the Chinese socialist youths with the theoretical system of Chinese characteristics socialism. Guide young people armed themselves with scientific theories, set up the lofty aspirations, persist the belief of walking the road of socialism China characteristics; guide the youth to shape their own with the noble spirit, hold high the banner of patriotism, collectivism, and socialism, carry forward the fine traditional culture of the Chinese nation, consciously abide by the social morality and the occupation moral.

\section{B.on the guide manners, need enriching and expanding}

Steading the traditional method, innovating the activities .Inheritance and innovation just like the two sides of a coin, lack of effective innovation, traditional work projects will gradually lose its vitality; lack of the adherence to effective practices and traditional inheritance, innovation will become a source of water. Ideological guidance should to rely on a long stick work, accumulated bit by bit in order to see results. We need to carry out a long-term, theme educational activities and social practice, need to explore and innovate various sets of active forms, which are thoughtful, informative, interesting and entertaining, using various means to carry out the youth ideological guidance.

Emphasis on practical education, improve the education system in practice. Practice is the best channels and inevitable theory with practice, that is, to let the young socialist core value system of the theories and concepts associated with real life, so as to create conditions for raising awareness, deepen understanding, and firm belief. For example , "My Chinese Dream", "Motherland and I forge ahead, "learn from Lei Feng, volunteers, and other topics of educational practice. Play practical advantages of educating people, we should fully respect the practice of youth participation in the dominant position. For the subjective consciousness of contemporary youth to participate in the growing awareness of the characteristics inherent attention to mobilizing the enthusiasm of youth and creativity to guide the youth in the practice of self-experience, self-education, self-improvement,in the transformation of the objective world while transforming the subjective world.

\section{C.the guiding mechanism, efforts to form the longitudinal and transverse forces.}

To establish a set of strict ideological guidance of youth work and levels of accountability. Youth should work into the ideological guidance of the special events group among the groups themselves into construction. In the whole group to advocate scientific achievements, the establishment of a sound assessment mechanism thought to guide the work of the youth, to grasp wether the real is real ideological or not , and moral education of the young, as if politics is an important criterion, as measured by a group important basis for the work of cadres level and work performance.

Establish the group linkage mechanism. To make full use of social resources, extensive coordination of the forces, the integration of work groups on all fronts, to give full play groups are service positions, the role of service projects, the configured resources to good use, to achieve the provincial, city and county three League information exchange, resource sharing within the group linkage mechanism.

Forming the social work force. Adhere to the party's unified leadership group in charge of the organization, and the Party Committee Propaganda Department, education, culture, women' s federations and other units and departments, and social forces to work together in close collaboration, to build young people's ideological linkage mechanism to guide the work of the community, and make concerted efforts to form a strong, wide coverage of youth ideological and political work network.

\section{D.on the guide means, play social media, the role of the media group is to create a good atmosphere.}

Fully take use of modern media technology, accelerate the ideological guidance of youth work support updates. The main use for the network is the actual population of young people, young people thought to play dynamic network control and the role of youth education and guidance, and actively occupied this new youth education positions. Increase the positive impact of online publicity, solidarity,attract,gather and compete for the youth, the Internet into a position to carry out an effective ideological guidance of youth work.

Fully take advantage of the power of new social media work. Contact Youth League should be good to play a tight, complete organizational system advantages, strengthen cooperation and youth generally clustered sites, communities and mobile communications operators and other new social media agencies, with their channel sand influence, through a joint organization to carry out propaganda theme activities to 
promote ideological caucus advocates better ties and guide young people.

Focus on the use of micro-blogging, letters and other new media tools to work. Positive energy to better achieve ideological guidance function, one should strive to train and support a number of large fans, by the youth concerned about the high and influential organizations, individuals micro-blogging, through these micro-blog, online dissemination of ideas. On the other hand to highlight the ideological content micro-blogging, through the youth of common concern, interpretation and young talent is closely related to social events, to guide young people to develop a more rational, comprehensive and profound social observation conclusions. Hobbies and needs to adapt to local youth, clearly positioning itself to develop new features, new content, by carrying out activities in a variety of networking topics, impact and cover the majority of youth.

\section{REFERENCES}

[1]Chen XinWen, the Communist Youth League Service Youth Supply Me chanism Research- For example, Fo Shan[J]. Chinese Youth Research, vol. 6 2010(2):17-19

[2]Wang Chunhua, New Era Higher School the Communist Youth League Work Path Reserch[D], Shan Dong University, 2011(6):31-33.

[3]zhanghua.the Reseach on Chinese Communist Youth League functions[D].Southwest University,2011(3):14-17.

[4]Zhang Yuwen.Under the Leadership of the Party The Youth Organization in Hunan Construction Problems and Countermeasures[D].hunan Normal University .2011(5):34-36

[5]Zhang Zihan. Challenges and Solutions of the Communist Youth League in Internet Age. [D].Shandong Univrsity,2011

[6]Lihao.The Study of Project Management Theory's Applying in Work of Communist Youth Leagur of Universities. [D].China University of Geosciences（Beijing）,2012 